\title{
Diet and Brain Health ${ }^{1}$
}

\author{
Pooja Tolani and Wendy J. Dahl
}

Following a healthful diet provides many benefits throughout the life cycle. Maintaining good eating habits as we age can be especially helpful to preserve cognitive health-the ability to remember, learn, and make decisions. This publication provides tips for healthful eating that may help to maximize brain health in older adults.

\section{Which foods should I eat to support brain health?}

Dietary patterns that are best known for promoting heart health may also be beneficial for brain health. The Mediterranean dietary pattern emphasizes whole grains, legumes, vegetables, fruits, nuts, olive oil, and fish, as well as moderate amounts of meat and dairy products (Widmer et al. 2015). This dietary pattern also includes wine, although it is not recommended to start consuming alcohol if one has not done so previously. Following a Mediterranean dietary pattern has been linked to a lower risk of cognitive decline, Alzheimer's disease, and other forms of dementia (van de Rest et al. 2015) and may improve cognitive function in older adults (Valls-Pedret et al. 2015).

Another dietary pattern that may be beneficial for brain health is the DASH diet (Dietary Approaches to Stop Hypertension) (Solfrizzi et al. 2017), a diet that is recommended for decreasing blood pressure and heart disease risk (Siervo et al. 2015). The DASH diet focuses on fruits, vegetables, low-fat dairy products, whole grains, poultry, fish, and nuts. Individuals following this dietary pattern are encouraged to limit their intake of red meat, sweets, sugar-containing beverages, and foods high in saturated fat.

As foods recommended in the Mediterranean diet and the DASH diet have been found to be helpful in maintaining brain health, combining the foods recommended in each of these dietary patterns may be even more beneficial. The MIND diet (Mediterranean-DASH Intervention for Neurodegenerative Delay) has been tested for its effectiveness to protect brain health. This diet focuses on more plant-based foods and less animal-derived foods (Marcason 2015). Following the MIND diet has been linked to a decreased risk for developing Alzheimer's disease (Morris et al. 2015).

Table 1 shows foods that may be helpful for protecting brain health (Marcason 2015). Aim for at least 5 servings of vegetables each day, especially green leafy (e.g. spinach, collards, and kale) and cruciferous vegetables (e.g. broccoli, cabbage, and Brussel sprouts). Target at least 4 servings of fruits each day, choosing berries often. Omega-3 fatty acids, found in foods such as olive oil, walnuts, and fatty fish (e.g. salmon, tuna, and sardines) help to maintain brain health. Choose unsalted nuts or nut butter most every day. A meal based on legumes (e.g. chickpeas, lentils, and various beans) is recommended at least twice a week. Choose fish at least 3 times a week. For information on recommended servings of foods for promoting brain health, please see the Brain Health Food Guide at http://www.baycrest.org/ wp-content/uploads/BHFG_optimized.pdf.

1. This document is FSHN18-1, one of a series of the Food Science and Human Nutrition Department, UF/IFAS Extension. Original publication date January 2018. Visit the EDIS website at http://edis.ifas.ufl.edu.

2. Pooja Tolani, dietetic intern; and Wendy J. Dahl, associate professor; Food Science and Human Nutrition Department, UF/IFAS Extension, Gainesville, FL 32611.

The Institute of Food and Agricultural Sciences (IFAS) is an Equal Opportunity Institution authorized to provide research, educational information and other services only to individuals and institutions that function with non-discrimination with respect to race, creed, color, religion, age, disability, sex, sexual orientation, marital status, national origin, political opinions or affiliations. For more information on obtaining other UF/IFAS Extension publications, contact your county's UF/IFAS Extension office. 
Table 1. Foods to increase to promote brain health.

\begin{tabular}{|l|l|}
\hline $\begin{array}{l}\text { Brain- } \\
\text { healthy } \\
\text { Foods }\end{array}$ & Examples \\
\hline $\begin{array}{l}\text { Green leafy } \\
\text { vegetables }\end{array}$ & $\begin{array}{l}\text { Spinach, kale, collards, Swiss chard, mustard greens, } \\
\text { turnip greens, dandelion greens, arugula, endive, } \\
\text { grape leaves, romaine lettuce }\end{array}$ \\
\hline Vegetables & $\begin{array}{l}\text { Asparagus, broccoli, Brussels sprouts, cabbage, } \\
\text { carrots, cauliflower, eggplant, onions, okra, snow } \\
\text { peas, squash, bell peppers, sweet potatoes, } \\
\text { tomatoes }\end{array}$ \\
\hline Nuts & $\begin{array}{l}\text { Walnuts, peanuts, almonds, cashews, pistachios, or } \\
\text { nut butter }\end{array}$ \\
\hline Berries & Blueberries, strawberries, raspberries, blackberries \\
\hline Legumes & $\begin{array}{l}\text { Black, pinto, cannellini, garbanzo (chickpea), kidney, } \\
\text { lima, red/white, and navy beans; lentils, edamame, } \\
\text { hummus }\end{array}$ \\
\hline Whole grains & $\begin{array}{l}\text { Whole grain bread, brown rice, whole grain pasta, } \\
\text { wild rice, quinoa, barley, bulgar, oats, whole grain } \\
\text { breakfast cereals }\end{array}$ \\
\hline Fish & $\begin{array}{l}\text { Salmon, tuna, tilapia, sardine, mahi mahi, halibut } \\
\text { Extra virgin olive oil }\end{array}$ \\
\hline Oil & \\
\hline
\end{tabular}

\section{Which foods should I limit to support brain health?}

The MIND dietary pattern emphasizes eating more plantbased foods and limiting animal foods that are high in saturated fat. Saturated fats are solid at room temperature and are found in animal products like butter, cream, and the fat within and around meat, as well as in margarine and bakery and snack foods made with hydrogenated vegetable oils. To promote brain health, avoid store-bought baked foods such as donuts, cakes, and cookies, as well as sugary and salty snacks and most pre-packaged, frozen, and canned meals. In the Brain Health Food Guide, it is recommended to limit meat and poultry to no more than one meal per day, and red and processed meats to less than once a week. Table 2 lists food that should be limited or avoided to protect brain health (Marcason 2015).

Table 2. Foods to limit to promote brain health.

\begin{tabular}{|c|c|}
\hline Foods to Limit & Examples \\
\hline $\begin{array}{l}\text { Red meat and } \\
\text { processed meat }\end{array}$ & $\begin{array}{l}\text { Beef, lamb, pork, ham, burgers, hot dogs, } \\
\text { sausages, bacon, salami }\end{array}$ \\
\hline $\begin{array}{l}\text { Fats - solid at room } \\
\text { temperature }\end{array}$ & Butter, stick margarine \\
\hline Cheese & Full fat cheeses \\
\hline Pastries and sweets & $\begin{array}{l}\text { Biscuits, cakes, sweet rolls, pastries, donuts, } \\
\text { cookies, brownies, pies, candy bars, other } \\
\text { candy, ice cream, sugary beverages }\end{array}$ \\
\hline Fried or fast foods & $\begin{array}{l}\text { Fast food or fast-casual restaurants } \\
\text { Any fried foods, including potato chips }\end{array}$ \\
\hline
\end{tabular}

\section{Should I be concerned about specific nutrients?}

As we age, there is an increased risk for vitamin B12 deficiency. As vitamin B12 helps to keep the brain and nervous system healthy, it is important to consume animalsourced foods containing vitamin B12, such as dairy foods, meat, fish, poultry, and eggs. For those who consume only plant-sourced foods, it is recommended to choose foods fortified with vitamin B12 or take a vitamin B12 supplement. Some examples of foods that may be fortified with vitamin B12 include non-dairy milks (e.g. soy milk), meat substitutes (e.g. tofu), and certain breakfast cereals.

Older adults who eat adequate amounts of vegetables, fruits, whole grains, fish, and low-fat dairy products tend to have better nutritional status and overall quality of life (Bernstein and Munoz 2012). Similarly, the MIND diet emphasizes these important food groups and may help to delay or prevent memory decline and brain-related diseases, such as Alzheimer's disease (Morris et al. 2015). Including a wide variety of foods from the Mediterranean, DASH, and MIND dietary patterns may be beneficial for brain health, and will also provide the nutrients needed to support overall health.

\section{References}

Bernstein, M., and N. Munoz. 2012. "Position of the Academy of Nutrition and Dietetics: food and nutrition for older adults: promoting health and wellness." J Acad Nutr Diet 112 8):1255-77. doi: 10.1016/j.jand.2012.06.015.

Marcason, W. 2015. "What Are the Components to the MIND Diet?" J Acad Nutr Diet 115(10):1744. doi: 10.1016/j. jand.2015.08.002.

Morris, M.C., C.C. Tangney, Y. Wang, F.M. Sacks, D.A. Bennett, and N.T. Aggarwal. 2015. "MIND diet associated with reduced incidence of Alzheimer's disease." Alzheimers Dement 11(9):1007-14. doi: 10.1016/j.jalz.2014.11.009.

Siervo, M., J. Lara, S. Chowdhury, A. Ashor, C. Oggioni, and J.C. Mathers. 2015. "Effects of the Dietary Approach to Stop Hypertension (DASH) diet on cardiovascular risk factors: a systematic review and meta-analysis." Br J Nutr 113(1):1-15. doi: 10.1017/s0007114514003341.

Solfrizzi, V., C. Custodero, M. Lozupone, B.P. Imbimbo, V. Valiani, P. Agosti, A. Schilardi, A. D’Introno, M. La Montagna, M. Calvani, V. Guerra, R. Sardone, D. I. Abbrescia, A. Bellomo, A. Greco, A. Daniele, D. Seripa, G. Logroscino, 
C. Sabba, and F. Panza. 2017. "Relationships of Dietary Patterns, Foods, and Micro- and Macronutrients with Alzheimer's Disease and Late-Life Cognitive Disorders: A Systematic Review." J Alzheimers Dis 59(3):815-849. doi: 10.3233/jad-170248.

Valls-Pedret, C., A. Sala-Vila, M. Serra-Mir, D. Corella, R. de la Torre, M.A. Martinez-Gonzalez, E.H. MartinezLapiscina, M. Fito, A. Perez-Heras, J. Salas-Salvado, R. Estruch, and E. Ros. 2015. "Mediterranean Diet and Age-Related Cognitive Decline: A Randomized Clinical Trial." JAMA Intern Med 175(7):1094-103. doi: 10.1001/ jamainternmed.2015.1668.

van de Rest, O., A.A. Berendsen, A. Haveman-Nies, and L.C. de Groot. 2015. "Dietary patterns, cognitive decline, and dementia: a systematic review." Adv Nutr 6(2):154-68. doi: 10.3945/an.114.007617.

Widmer, R.J., A.J. Flammer, L.O. Lerman, and A. Lerman. 2015. "The Mediterranean diet, its components, and cardiovascular disease." Am J Med 128(3):229-38. doi: 10.1016/j.amjmed.2014.10.014. 